\title{
Hybrid artificial intelligence-based bond strength model of CFRP-lightweight concrete composite
}

\author{
Emmanuel Macabenta Lazo ${ }^{1}$, and John Pepard Mendoza Rinchon ${ }^{1, *}$ \\ ${ }^{1}$ Civil Engineering Department, College of Engineering, Technological Institute of the Philippines, Quezon City, Philippines 1109
}

\begin{abstract}
Different retrofitting techniques are commonly used to sustain the design life of heavy damage and deteriorated concrete structures, whilst epoxy-bonded carbon fiber reinforced polymer (CFRP) has emerged as a widely known retrofitting method. Consequently, a sound understanding of the bond strength between structural lightweight concrete (LWC) and CFRP based on influential factors is essential in safety and economic requirements. In this study, a hybrid bond strength model using the artificial neural network (ANN) and genetic algorithm (GA) was developed to furtherly understand the bond of a CFRP strengthened LWC structure. ANN was able to establish under satisfactory performance the relationship between the maximum bond load and the following influential parameters: width of CFRP $\left(b_{f r p}\right)$, total CFRP bond length $\left(L_{f r p}\right)$, CFRP thickness $\left(t_{f r p}\right)$, and CFRP angle of orientation $\left(\theta_{f r p}\right)$. Furthermore, GA was able to derive the optimal configuration of the influential parameters resulted in high bond performance. Moreover, the optimization results also validated the sensitivity of each parameter on the interfacial bond behavior between LWC and CFRP.
\end{abstract}

\section{Introduction}

Rapid deterioration, excessive seismic damage, and outdated design codes and provisions of concrete infrastructure become the principal challenges of all nations worldwide. In response to these challenges, repair and strengthening of existing concrete structures became the solutions in order to still meet the required ultimate load carrying capacity and serviceability. Consequently, carbon fiber reinforced polymer (CFRP) has emerged as one of the notable accepted retrofitting materials of the civil engineering community in recent years [1]. Several studies account the success of CFRP as reinforcement in a wide variety of applications for different materials such as aluminum $[2,3]$, steel $[4,5]$, and concrete $[6-8]$. The utilization of CFRP as retrofitting material provides technically sound and cost-efficient due to its lightweight, resistance to corrosion, and ease of handling and installation [9-11]. CFRP can be in the form of laminates, sheets, or strips as shown in Fig. 1. Furthermore, CFRP has very advantageous mechanical properties of high specific strength and high specific stiffness compare to other strengthening materials [12].

On the other hand, interfacial debonding is concluded to be the most common mode of failure of CFRP strengthened concrete structures. According to Pellegrino et al. [13], the bond mechanism for effective stress transfer is vital in the performance of the CFRP-concrete composite. Sayed-Ahmed et al. [14] conducts an extensive investigation to review the different analytical models of bond strength between CFRP and concrete considering different parameters and assumptions. Furthermore, several studies have developed different prediction models on the bond strength of CFRP and concrete under different considerations [15-20]. Different modeling techniques are also utilized in developing the maximum bond load and bond strength prediction models [21-24].

However, previous studies focus only on the performance of CFRP on normal weight concrete even there is an apparent growing demand for the use of lightweight concrete (LWC) in construction projects over the past decades. Still, less attention is given in the investigation of bond performance between LWC and CFRP [9]. Thus, this present study aimed to model the underlying behavior of the bond strength performance between LWC and CFRP using a hybrid artificial intelligence (AI) model wherein recent studies [25-28] show its promising application in the field of civil engineering and construction materials. The study specifically aimed to develop a prediction model of the bond strength between LWC and CFRP using the artificial neural network (ANN); and to utilize genetic algorithm (GA) optimization in producing high bond strength performance between LWC and CFRP.

\section{Materials and Methods}

\subsection{Double Lap Shear (DLS) Test Datasets}

In this study, a total of fifty-five datasets from the double lap shear (DLS) test were retrieved from the paper published by Al-Allaf et al. [9] (Refer to table 1). These

\footnotetext{
Corresponding author: jprinchon27@gmail.com
} 
datasets were summarized and utilized as the primary input in the development of the hybrid model. The following factors considered by Al-Allaf et al. [9] in the DLS test such as the width of CFRP $\left(b_{f r p}\right)$, total CFRP bond length $\left(L_{f r p}\right)$, CFRP thickness $\left(t_{f}\right)$, and CFRP angle of orientation $\left(\theta_{f r p}\right)$ were also used in this study as the influential parameters for the prediction of bond strength between LWC and CFRP.

\subsection{Hybrid Neural Network-Genetic Algorithm}

The development of hybrid bond strength model was composed of two stages namely the ANN modeling and the GA optimization. Generally, ANN was utilized to develop a prediction model that established the relationship between the maximum bond load $\left(P_{\max }\right)$ and the influential parameters. The neural network for the maximum bond load between LWC and CFRP was developed using the simplest and widely used ANN model known as the feedforward multilayered supervised neural network with error back-propagation algorithm. The network was structured based on the following internal parameters such as the training algorithm, transfer function, number of hidden layers, and number of neurons per hidden layer. The Levernberg-Marquardt (LM) algorithm and hyperbolic tangent sigmoid function or tansig function were utilized as training algorithm and transfer function respectively. The number of the hidden layer was set at one and the number of neurons per hidden layer was based on the value proposed by Asteris et al. [29]. Moreover, the predicting performance of the neural network was assessed based on Pearson correlation coefficient (R) and mean square error (MSE) while the topology of the bond strength neural network model was constructed and run using MatLab® R2015a software.

The GA was deployed for the purpose of optimizing the independent variables in Equation 1 that will yield a high bond load performance. The objective function and the corresponding constraints for the GA optimization are expressed as follows:

$$
\begin{gathered}
\text { Maximize: } P_{\max }=f\left(b_{f r p}, L_{f r p}, t_{f}, \theta_{f r p}\right) \\
50 \leq b_{f r p} \leq 150 \\
100 \leq L_{f r p} \leq 200 \\
0.1178 \leq t_{f} \leq 0.2356 \\
0 \leq \theta_{f r p} \leq 90
\end{gathered}
$$

The $P_{\max }$ is the prediction model developed during the first stage of the hybrid model. Equations 2 to 5 were used as constraints for the algorithm intended to search for the global and realistic solution of the optimization problem. Furthermore, the genetic algorithm was formed based on the procedure originally proposed by Goldberg [30]. This algorithm is generally composed of three genetic operators namely the selection, mutation, and crossover. In this study, the stochastic uniform method was used as the selection operator while the adaptive feasible model was utilized as mutation operator. Moreover, scattered and one-point models were explored as crossover operators.

\section{Results and Discussions}

After several simulations, the final topology of the bond strength prediction model of the LWC-CFRP composite was structured. The final model was composed of three neurons with one hidden layer. The biases and weights for the input layer of the final ANN architecture are given by Equations 6 to 7 respectively, while for the hidden layer, Equations 8 and 9 represent the biases and weights respectively.

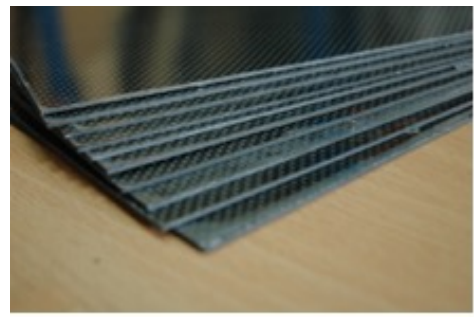

(a)

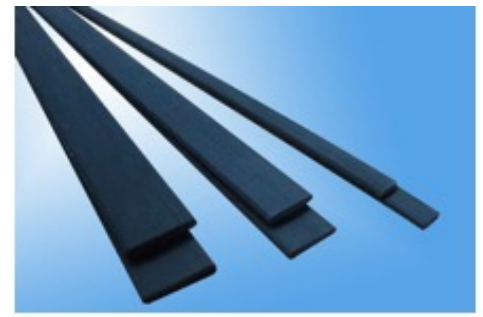

(b)

\begin{tabular}{|c|c|c|c|c|}
\hline \multirow{2}{*}{ Variable } & \multicolumn{4}{|c|}{ Details of Variable } \\
\hline & Minimum & Maximum & Range & Mean \\
\hline \multicolumn{5}{|l|}{ Input } \\
\hline CFRP width, $b_{f r}(\mathrm{~mm})$ & 50 & 150 & 100 & 100 \\
\hline Total CFRP bond length, $L_{f r p}(\mathrm{~mm})$ & 100 & 200 & 100 & 130 \\
\hline CFRP thickness, $t_{f}(\mathrm{~mm})$ & 0.1178 & 0.2356 & 0.1178 & 0.1392 \\
\hline CFRP angle of orientation, $\theta_{f r p}\left({ }^{\circ}\right)$ & 0 & 90 & 90 & 22.91 \\
\hline \multicolumn{5}{|l|}{ Output } \\
\hline Test failure load, $P_{\text {test }}(\mathrm{kN})$ & 0.47 & 29.69 & 29.22 & 18.87 \\
\hline
\end{tabular}

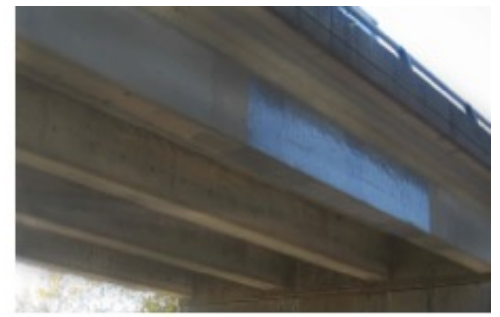

(c)

Fig. 1. Forms of CFRP (C2017 Google Image: (a) sheets, (b) strips, and (c) laminates

Table 1. Summary of ANN input and output parameters. Retrieved from Al-Allaf [9] 

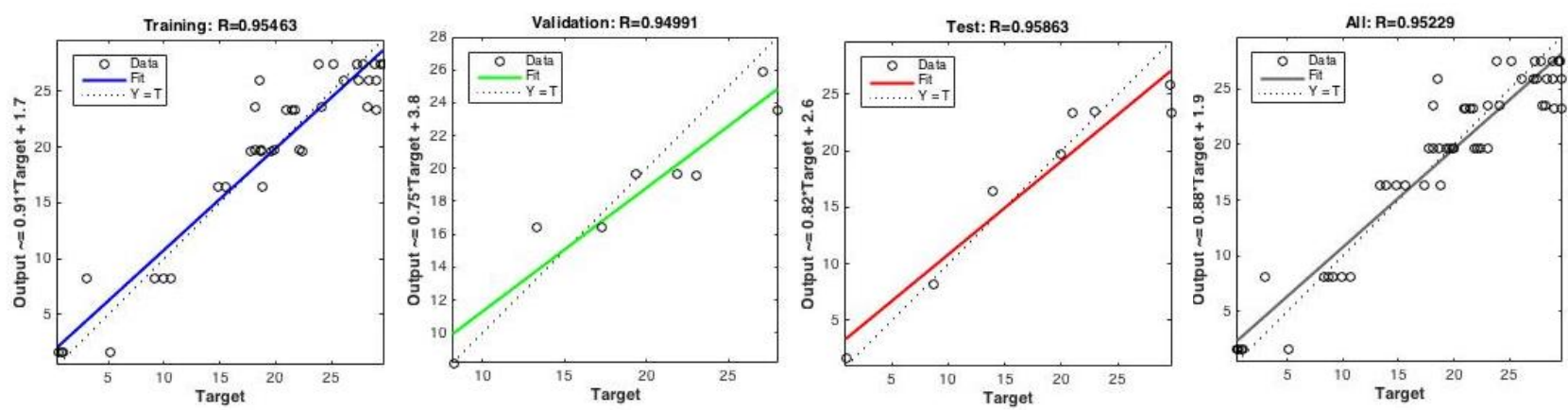

Fig. 2. Pearson correlation coefficient performance of the bond strength neural network

$$
\begin{gathered}
b_{I}=\left[\begin{array}{c}
3.31225 \\
1.96781 \\
-3.86852
\end{array}\right] \\
W_{I}=\left[\begin{array}{cccc}
2.75362 & 3.78588 & -0.034438 & -1.92568 \\
-1.84853 & 1.472366 & 2.019534 & -0.55476 \\
-6.91359 & 0.52008 & 0.58746 & -4.14345
\end{array}\right] \\
b_{H}=\left[\begin{array}{lll}
-0.42735
\end{array}\right] \\
W_{H}=\left[\begin{array}{lll}
0.72335 & 0.63921 & -0.83450
\end{array}\right]
\end{gathered}
$$

The performance of the final ANN bond strength prediction model was remarkably high at 0.95 correlation coefficient. This was also evident based on the correlation coefficients of the training, validation and testing stages with values greater than 0.95 as shown in Fig. 2. Additionally, LM Algorithm and Tansig Function were still proven to be high performing training algorithm and transfer function respectively in the present study.

For GA optimization, the optimal combination of the influential parameters (i.e. $b_{f r p}=91.5 \mathrm{~mm}, L_{f r p}=200 \mathrm{~mm}$, $t_{f}=0.2356$, and $\theta_{f r p}=90^{\circ}$ ) for high bond load performance was determined for over 200 generations as shown in Fig. 3 . Based on this combination, the optimization procedure was able to yield a maximum bond load of $P_{\max }=40 \mathrm{kN}$. Furthermore, it is observed that larger values of the CFRP's total bond length, thickness, and angle of orientation increase the bond load while increasing the width of the CFRP sheet provides limited benefit on the bond load capacity.

\section{Conclusion}

Further investigation of the interfacial bond behavior of LWC with externally bonded CFRP using previously proposed hybrid model was studied in this research. At this point, the hybrid neural network-genetic algorithm was able to provide satisfactory results in terms of developing the bond strength prediction model and optimization of the considered influential parameters. Satisfactory establishment of the relationship between the influential parameters and the bond load was completely achieved based on justifiable Pearson correlation coefficient. Moreover, the optimization results showed that each influential parameter has a different effect on the bond quality between LWC and CFRP, wherein the orientation of the CFRP sheet $\left(\theta_{f r p}\right)$ greatly affects the shear distribution of load to the fiber of CFRP sheet.

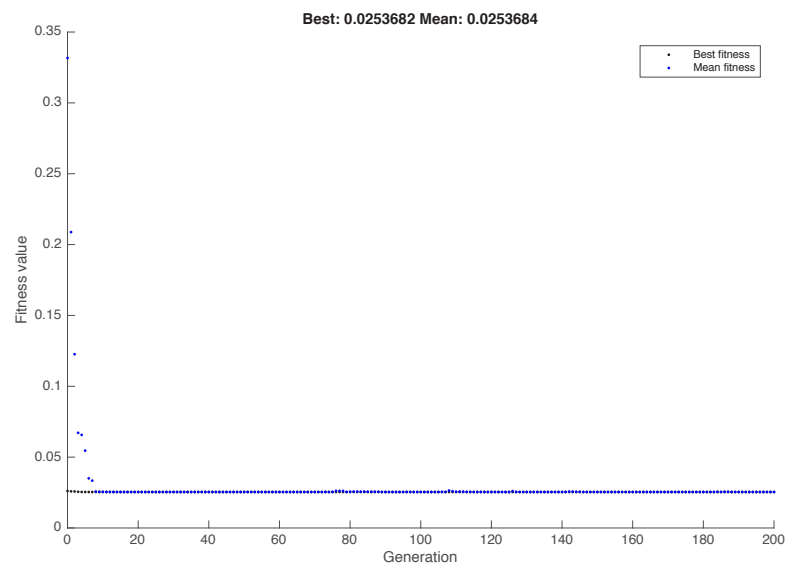

Fig. 3. Results of genetic algorithm optimization

\section{References}

[1] P. Sarker, M. Begum, and S. Nasrin, "Fibre reinforced polymers for structural retrofitting: A review," J Civil Eng, vol. 39, no. 1, pp. 49-57, 2011.

[2] U. Tamilarasan, L. Karunamoorthy, and K. Palanikumar, "Mechanical Properties Evaluation of the Carbon Fibre Reinforced Aluminium Sandwich Composites," Materials Research, vol. 18, no. 5, pp. 1029-1037, 2015.

[3] J. Wang et al., "Bond strength between carbon fiberreinforced plastic tubes and aluminum joints for racing car suspension," Advances in Mechanical Engineering, vol. 8, no. 10, p. 1687814016674627 , 2016.

[4] M. Kamruzzaman, M. Z. Jumaat, N. Ramli Sulong, and A. Islam, "A review on strengthening steel beams using FRP under fatigue," The Scientific World Journal, vol. 2014, 2014.

[5] A. Shaat, D. Schnerch, A. Fam, and S. Rizkalla, "Retrofit of steel structures using fiber-reinforced polymers (FRP): State-of-the-art," in Transportation research board (TRB) annual meeting. CD-ROM (044063), 2004. 
[6] A. Belarbi and B. Acun, "FRP systems in shear strengthening of reinforced concrete structures," Procedia Engineering, vol. 57, pp. 2-8, 2013.

[7] A. Belarbi, M. Reda, P. Poudel, H. Tahsiri, M. Dawood, and B. Gencturk, "Prestressing Concrete with CFRP Composites for Sustainability and Corrosion-Free Applications," in MATEC Web of Conferences, 2018, vol. 149, p. 01010: EDP Sciences.

[8] A. S. Karzad, S. Al Toubat, M. Maalej, and P. Estephane, "Repair of reinforced concrete beams using carbon fiber reinforced polymer," in MATEC Web of Conferences, 2017, vol. 120, p. 01008: EDP Sciences.

[9] M. H. Al-Allaf, L. Weekes, L. Augusthus-Nelson, and P. Leach, "An experimental investigation into the bond-slip behaviour between CFRP composite and lightweight concrete," Construction and Building Materials, vol. 113, pp. 15-27, 2016.

[10] S. E. Günaslan, A. Karaşin, and M. E. Öncü, "Properties of FRP Materials for Strengthening," International Journal of Innovative Science, Engineering \& Technology, vol. 1, no. 9, 2014.

[11]S. Rizkalla and T. Hassan, "Various FRP strengthening techniques for retrofitting concrete structures," in CICE 2001 Conference proceedings, 2001.

[12] M. R. Piggott, Load bearing fibre composites, 2nd ed. Boston: Kluwer Academic Publishers, 2002, pp. xii, $475 \mathrm{p}$.

[13]C. Pellegrino, D. Tinazzi, and C. Modena, "Experimental study on bond behavior between concrete and FRP reinforcement," Journal of Composites for Construction, vol. 12, no. 2, pp. 180189, 2008

[14] E. Sayed-Ahmed, R. Bakay, and N. Shrive, "Bond strength of FRP laminates to concrete: state-of-the-art review," Electronic Journal of structural engineering, vol. 9, no. 1, pp. 45-61, 2009.

[15]C. Arya and N. Farmer, "Design guidelines for flexural strengthening of concrete members using FRP composites," in FRPRCS-5: Fibre-reinforced plastics for reinforced concrete structures Volume 1: Proceedings of the fifth international conference on fibre-reinforced plastics for reinforced concrete structures, Cambridge, UK, 16-18 July 2001, 2001, pp. 167-176: Thomas Telford Publishing.

[16]F. Externally Bonded, "Reinforcement for RC Structures," fib Bulletin, no. 14, pp. 51-58, 2001.

[17] M. A. Issa, M. Rahman, and R. Alrousan, "Prediction of Ultimate Load at the CFRP-Concrete Interface under Pure Shear Mode," International Journal of Composite Materials, vol. 6, no. 6, pp. 183-195, 2016.

[18]R. Seracino, M. Raizal Saifulnaz, and D. Oehlers, "Generic debonding resistance of EB and NSM plateto-concrete joints," Journal of Composites for Construction, vol. 11, no. 1, pp. 62-70, 2007.

[19]A. Serbescu, M. Guadagnini, and K. Pilakoutas, "Standardised double-shear test for determining bond of FRP to concrete and corresponding model development," Composites Part B: Engineering, vol. 55, pp. 277-297, 2013.

[20]C. Tuakta and O. Büyüköztürk, "Conceptual model for prediction of FRP-concrete bond strength under moisture cycles," Journal of Composites for Construction, vol. 15, no. 5, pp. 743-756, 2011.

[21] J. A. Abdalla, R. Hawileh, and A. Al-Tamimi, "Prediction of FRP-concrete ultimate bond strength using Artificial Neural Network," in Modeling, Simulation and Applied Optimization (ICMSAO), 2011 4th International Conference on, 2011, pp. 1-4: IEEE.

[22] J. Dai, T. Ueda, and Y. Sato, "Development of the nonlinear bond stress-slip model of fiber reinforced plastics sheet-concrete interfaces with a simple method," Journal of Composites for Construction, vol. 9, no. 1, pp. 52-62, 2005.

[23] J. L. Huang, P. Y. Huang, Z. W. Li, and X. H. Zheng, "Prediction of bond strength of FRP-concrete based on multiple linear regression method," in Advanced Materials Research, 2011, vol. 163, pp. 3623-3628: Trans Tech Publ.

[24] G. S. Tong and S. S. Chen, "Prediction Bond Strength between FRP and Concrete Interface by LEFM Method," in Advanced Materials Research, 2014, vol. 988, pp. 195-200: Trans Tech Publ.

[25] N. C. Concha and E. P. Dadios, "Optimization of the rheological properties of self compacting concrete using neural network and genetic algorithm," in Humanoid, Nanotechnology, Information Technology, Communication and Control, Environment and Management (HNICEM), 2015 International Conference on, 2015, pp. 1-6: IEEE.

[26] N. C. Concha, "Rheological Optimization of Self Compacting Concrete with Sodium Lignosulfate Based Accelerant Using Hybrid Neural NetworkGenetic Algorithm," in Materials Science Forum, 2016, vol. 866, pp. 9-13: Trans Tech Publ.

[27] J. P. M. Rinchon, N. C. Concha, and M. G. V. Calilung, "Reinforced concrete ultimate bond strength model using hybrid neural network-genetic algorithm," in Humanoid, Nanotechnology, Information Technology, Communication and Control, Environment and Management (HNICEM), 2017 IEEE 9th International Conference on, 2017, pp. 1-6: IEEE.

[28] J. P. M. Rinchon, "Strength Durability-Based Design Mix of Self-Compacting Concrete with Cementitious Blend using Hybrid Neural Network-Genetic Algorithm," IPTEK Proceedings Series, no. 6, 2017.

[29] P. Asteris, K. Kolovos, M. Douvika, and K. Roinos, "Prediction of self-compacting concrete strength using artificial neural networks," European Journal of Environmental and Civil Engineering, vol. 20, no. sup1, pp. s102-s122, 2016.

[30]D. E. Goldberg, "Genetic algorithms in search, optimization and machine learning 'addison-wesley, 1989," Reading, MA, 1989. 